\title{
Management of Fracture Mandible by Open Occlusal Acrylic Splint in Pediatric Patients: A Case Series
}

\author{
Tulsi G Lodhi ${ }^{1}$, Surendrakumar B Patil ${ }^{2}$, Surendrakumar K Bahetwar ${ }^{3}$, Pranali V Nimonkar ${ }^{4}$, Bhumika K Peter ${ }^{5}$, Aparna B Sharma ${ }^{6}$
}

\begin{abstract}
Aim and objective: The aim of this article is to report the treatment management of fracture mandible in pediatric patients by a simple, noninvasive, and conservative method. Treatment of a pediatric patient with a mandibular fracture is one of the most challenging jobs. In adults, the treatment of the mandibular fracture is a surgical intervention by open reduction and fixation but it is not usual in the case of children due to the anatomy of growing mandible and deciduous teeth, presence of underlying erupting permanent teeth, and incomplete ossification of jawbones. In pediatric patients, the main concern in the treatment of the mandibular fracture is the normal growth and development of mandibular bone. So, in this case series, the treatment of the children who got mandibular fracture were done by a simple, time saving and noninvasive procedure by the fabrication of open occlusal splint retained by circummandibular wiring which did not interfere with the growth and development of mandible.
\end{abstract}

Keywords: Occlusal splint, Pediatric mandibular fracture, Trauma.

International Journal of Clinical Pediatric Dentistry (2021): 10.5005/jp-journals-10005-2099

\section{INTRODUCTION}

Childhood is the time for children to play, learn, and grow. Play influences a child's life. Children are happy and enthusiastic while playing. But trauma while involved in the act of play is the most common amongst children. Though the reported incidence rate of facial fracture in children is $5 \%{ }^{1}$ due to the protective nature of anatomic features of the child's face. As in a child below 5 years, the midface and mandible are in retruded position, the condyle is short, the skull is prominent and the mandible is more flexible which reduces the incidence of mandibular fracture. ${ }^{2}$ but as the age increases above 5 years the facial growth takes place in forward and downward direction which increases the rate of midfacial and mandibular fracture.

In hospitalized pediatric patients the most common facial fracture noted was mandibular fracture ${ }^{3}$ reporting $32.7 \%$ followed by $30.2 \%$ of nasal bone fracture and $28.6 \%$ of midface/ zygoma fractures. ${ }^{4}$ In mandibular fracture condyle $(40-70 \%)$ is the most common site followed by symphyseal fracture (2-30\%) body, angle, and the ramus fracture. ${ }^{5} \mathrm{It}$ is seen more in a male child in all the age groups. ${ }^{6}$

According to Seiji lida and Tokuzo Matsuya, the most common etiologies of mandibular fracture were bicycle accidents (26\%), followed by falls $(25 \%)$ upto the age of 10 years but in patient older than 12 years assaults becomes the most common cause. ${ }^{7}$ Chitrita Mukherji and Uday Mukherjee noted that after accident and falls, the most common etiology is sport-related injury. ${ }^{8}$

In literature, various techniques for the treatment of mandibular fracture in adults are (1) closed reduction by arch bars, eyelet wires, or IMF screws. (2) Open reduction and internal fixation (ORIF) with mini plates, larger reconstruction plates, or lag screws are suggested. But in children, the treatment varies due to the anatomy of the growing mandible, anatomy of deciduous teeth, absence of some deciduous teeth due to exfoliation ${ }^{9}$, and presence of permanent tooth buds which does not permit the reduction of fracture mandible by plates, arch bar, and interdental ligature. $6,10,11$
1,2,6 Department of Plastic, Reconstructive and Maxillofacial Dentistry, Government Medical College and Hospital, Nagpur, Maharashtra, India ${ }^{3}$ Department of Pediatric and Preventive Dentistry, Government Dental College and Hospital, Nagpur, Maharashtra, India

${ }^{4}$ Department of Trauma Care Center, Government Medical College and Hospital, Nagpur, Maharashtra, India

${ }^{5}$ Department of Orthodontics, Bhaba Dental College and Research Center, Bhopal, Madhya Pradesh, India

Corresponding Author: Tulsi G Lodhi, Department of Plastic, Reconstructive and Maxillofacial Dentistry, Government Medical College and Hospital, Nagpur, Maharashtra, India, Phone: +91 7620619629, e-mail: drtulsilodhi@yahoo.com

How to cite this article: LodhiT, Patil SB, Bahetwar SK, et al. Management of Fracture Mandible by Open Occlusal Acrylic Splint in Pediatric Patients: A Case Series. Int J Clin Pediatr Dent 2021;14(6):812-815.

Source of support: Nil

Conflict of interest: None

So, the best conservative and non-invasive treatment in children for the fractured mandible is immobilization and closed reduction. In literature, the various suggested methods for closed reduction in pediatric patients are by using prefabricated open/closed cap splints, modified orthodontic brackets, orthodontic resin, and rubber elastics, and modified orthodontic splint appliance. ${ }^{4}$

So in this paper, we have highlighted the importance of management of mandibular fracture in a pediatric patient by open occlusal acrylic splint with the concern not to disturb the normal growth and development of the jaw and permanent tooth buds.

\section{Case Description}

A first case report is of 8-year boy who was reported to Trauma Care Center of Government Medical College and Hospital, Nagpur by his parents in an unconscious state with bleeding from the oral cavity. Parents gave a history that a child has fallen from the third-floor balcony while flying kite with his friends.

() The Author(s). 2021 Open Access This article is distributed under the terms of the Creative Commons Attribution 4.0 International License (https://creativecommons. org/licenses/by-nc/4.0/), which permits unrestricted use, distribution, and non-commercial reproduction in any medium, provided you give appropriate credit to the original author(s) and the source, provide a link to the Creative Commons license, and indicate if changes were made. The Creative Commons Public Domain Dedication waiver (http://creativecommons.org/publicdomain/zero/1.0/) applies to the data made available in this article, unless otherwise stated. 
Immediate medical examination of the child was carried out for any neurological problem and for any other injuries in the body. On examination, no neurological problem was noticed but both the hands of the child were fractured. Extraoral examination showed bilateral swelling and soft tissue laceration on the face. Intraoral examination (Fig. 1) showed step deformity at the inferior border of the right side of mandible mesial to deciduous canine with derangement in the occlusion cone beam computed tomography (CBCT) (Fig. 2) of the patient was carried out which revealed Para symphyseal fracture at the right deciduous canine region and left body fracture in mandible between left lower deciduous first and second molar. So, looking toward the age of the patient and concerned about the development of dentition and growth of mandible, the treatment plan for this patient was a closed reduction with an open occlusal acrylic splint. Treatment was explained to the patient's parents and consent was taken.

Then under General Anesthesia (G.A) the upper and lower arch impression was made with alginate impression material and the cast was obtained by pouring the impression with dental stone. Mock surgery was performed on the lower cast by sectioning the cast at the fracture site with the saw (Fig. 3) and then it was rejoined (Fig. 4) following the maximum intercuspation with the upper cast. The obtained casts were mounted on an articulator. An open occlusal acrylic splint was fabricated on the mandibular cast by reinforcing with 24 gauge orthodontic wire for strength. It was properly finished and polished.

Under general anesthesia, the fractured mandibular body was immobilized and then it was fixed with an open occlusal acrylic splint by retaining it with circummandibular wiring (Fig. 5). The patient's parents were advised to keep the patient on a soft diet and the instructions regarding the oral hygiene instruction were given to the parents. The patient was kept on follow-up after every week. After 3 weeks the open acrylic occlusal splint was removed. Orthopantomagram (OPG) (Fig. 6) was taken. The obtained occlusion was satisfactory. The patient was kept on follow-up for 6 months and was advised to take a soft diet and to maintain oral hygiene.

The second case is of 7-year boy who fall from a tree of a height of more than 10 feet due to which his mandible got fractured. The patient also got multiple injuries in brain, abdomen and kidney. CT head report showed hemorrhagic contusion involving the right medial lobe. USG abdomen report revealed renal injury with the perirenal collection and splenic contusion. CBCT of mandible showed a fracture at para symphyseal area mesial to deciduous lower right canine (Fig. 7). The patient was under treatment for brain, abdomen, and kidney injury. For fracture mandible, a conservative approach of treatment by open occlusal acrylic splint was planned for the patient (Fig. 8). CBCT of mandible was carried out after 3 weeks (Fig. 9).

In the third case, a 5-year girl patient met a road accident while playing on the side of the road. She got parasymphyseal fracture of the left side of the mandible (Fig. 10). So, the treatment was done successfully with an open acrylic occlusal splint (Fig. 11). All the instructions were given to the patient's parents. After 3 weeks the splint was removed.

\section{Discussion}

Treatment of mandibular fracture in children differs from the adult due to the anatomy of the primary dentition which does not allow the open reduction and immobilization by intermaxillary fixation

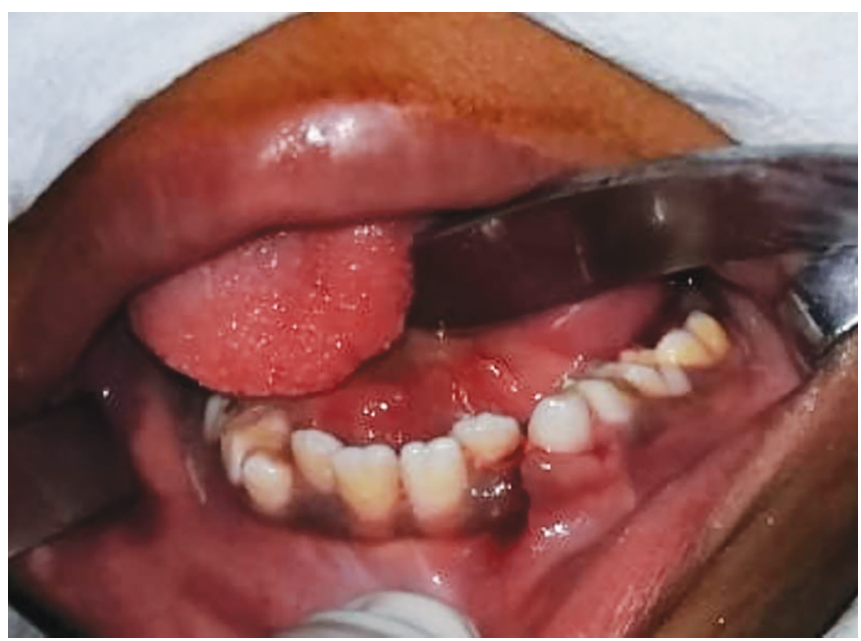

Fig. 1: Intraoral view showing step deformity at the inferior border of the right mandible

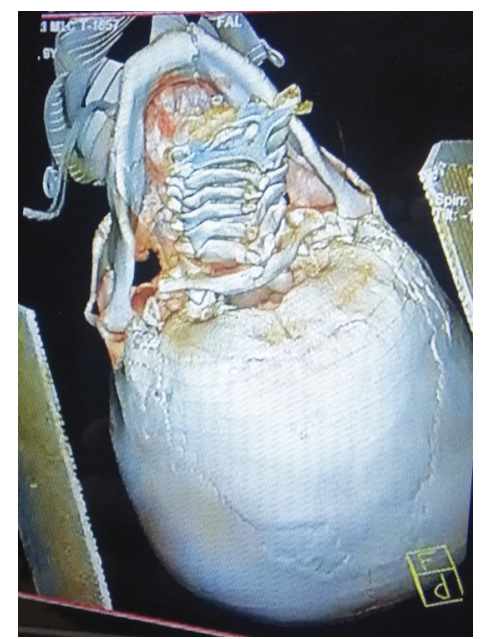

Fig. 2: $\mathrm{CBCT}$ of the mandible

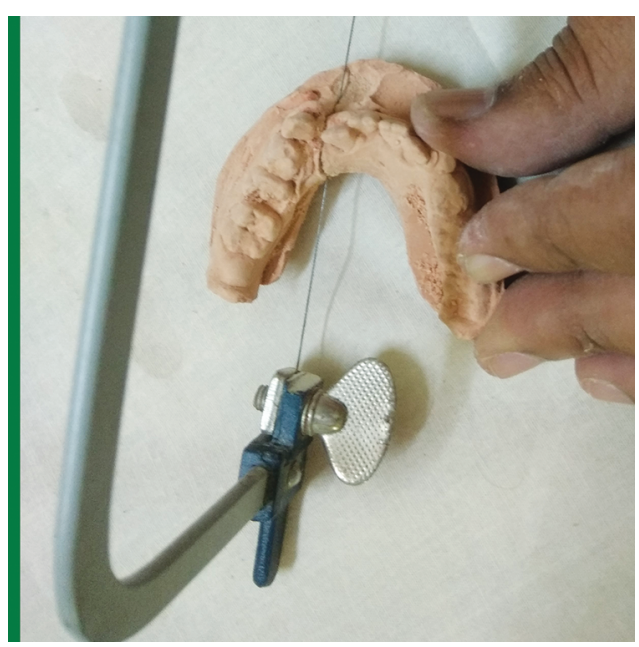

Fig. 3: Sectioning of lower cast

and due to anatomical complexity of growing mandible and the presence of growing permanent tooth germs which gets interfered and affected by the open reduction. ${ }^{6}$ So, the best conservative 


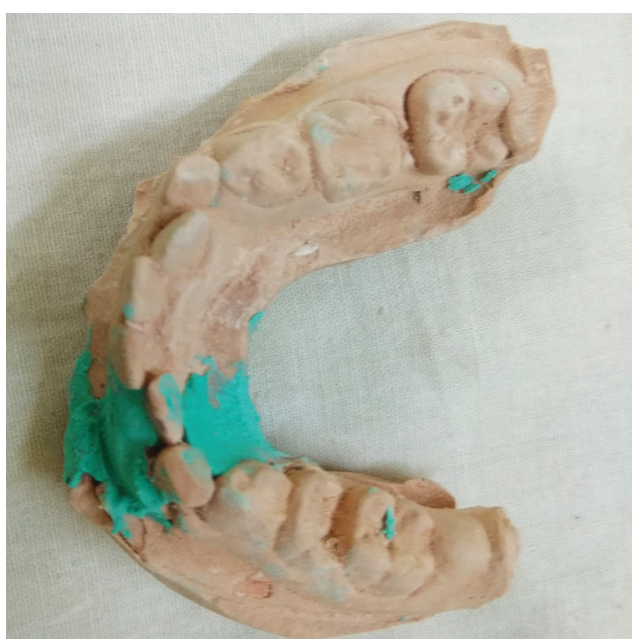

Fig. 4: Sectioned cast portion was rejoined with dental stone

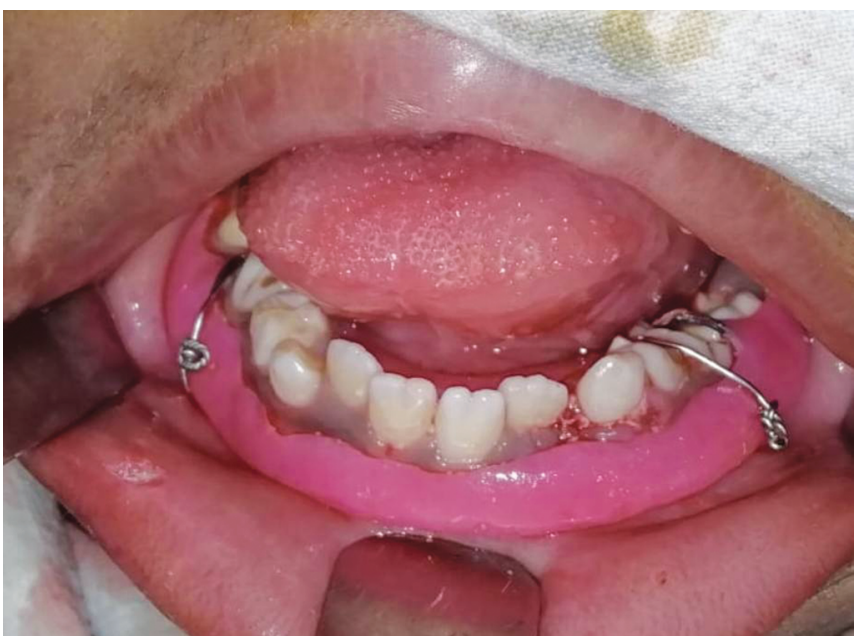

Fig. 5: Open occlusal acrylic splint with circummandibular wiring

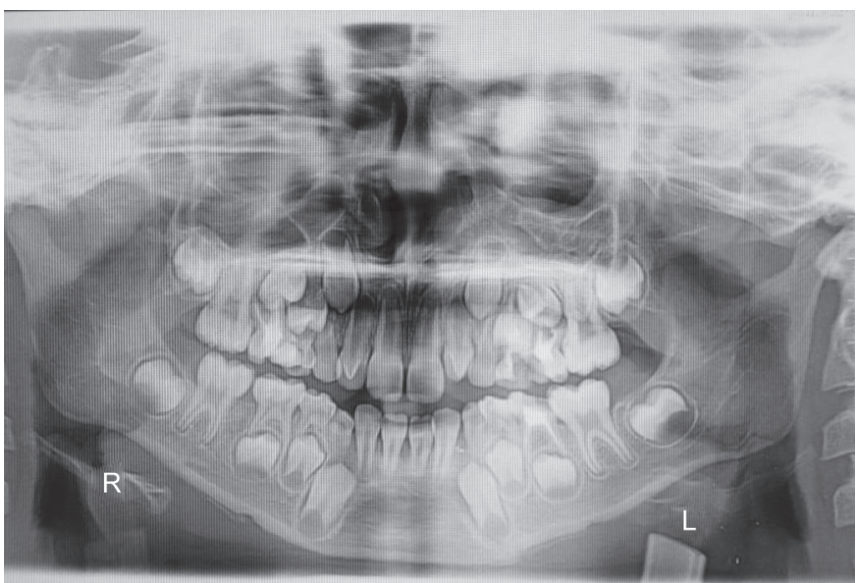

Fig. 6: OPG

and noninvasive treatment in children for the fractured mandible is immobilization and closed reduction. This is also supported by Niddhi Madan et al. In literature, the various suggested methods for closed reduction in pediatric patients are by using prefabricated open/closed cap splints, modified orthodontic brackets, orthodontic resin, and rubber elastics, and modified orthodontic splint appliance. ${ }^{4}$

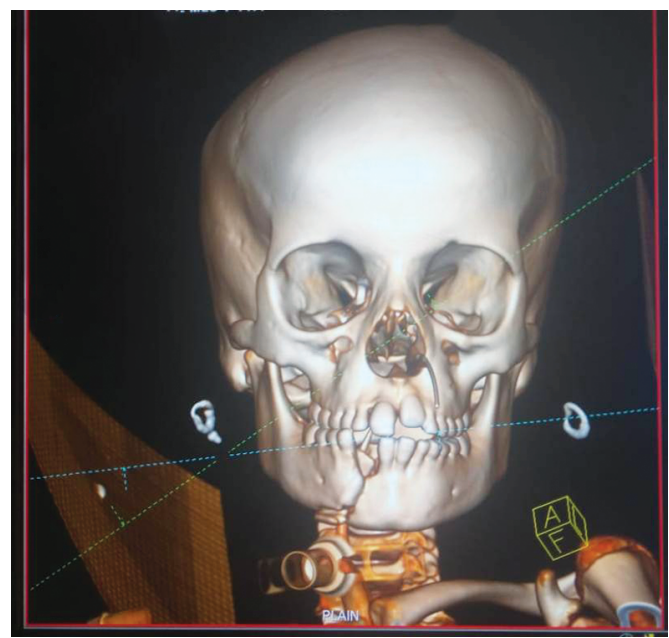

Fig. 7: $\mathrm{CBCT}$ of the mandible

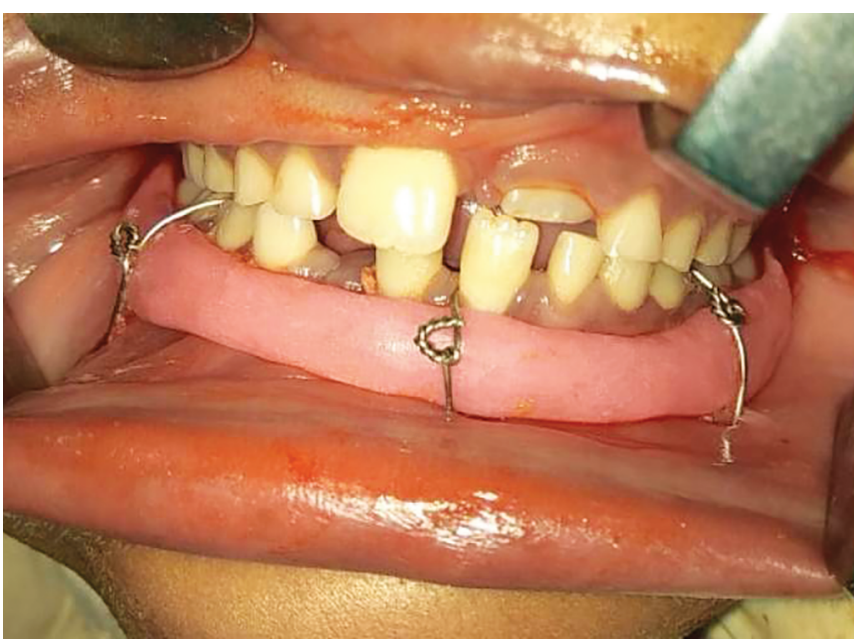

Fig. 8: Open occlusal splint retained with circummandibular wiring

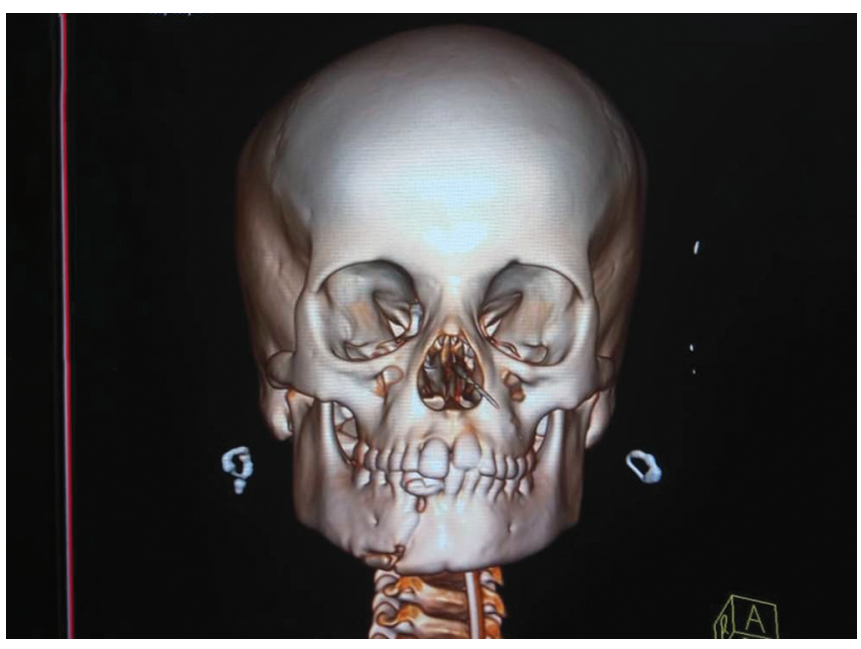

Fig. 9: $\mathrm{CBCT}$ of the mandible

\section{Conclusion}

In this case series, the pediatric patients of fracture mandible were treated by closed reduction using open occlusal splint which favors the rapid osteogenesis and remodeling by maintaining 


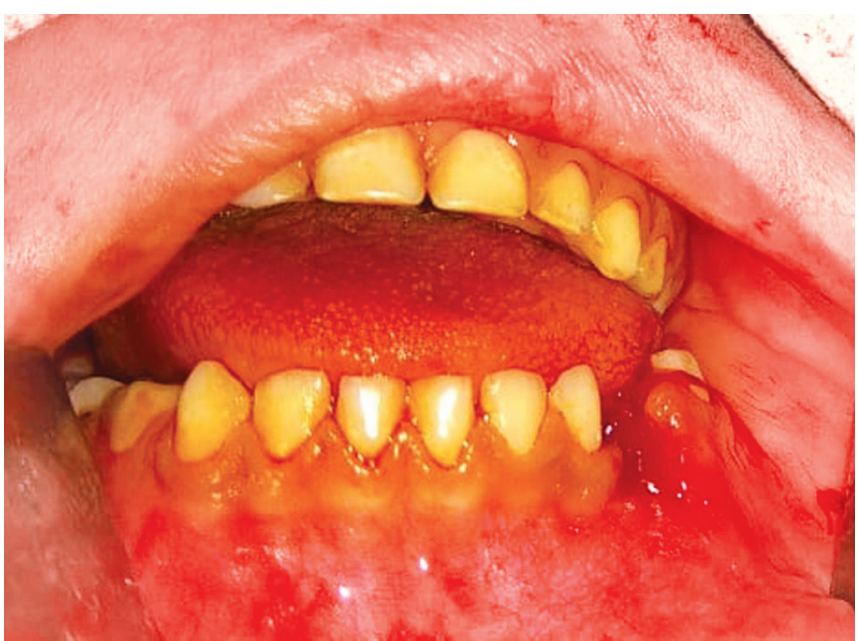

Fig 10: Parasymphyseal fracture of the left side of the mandible

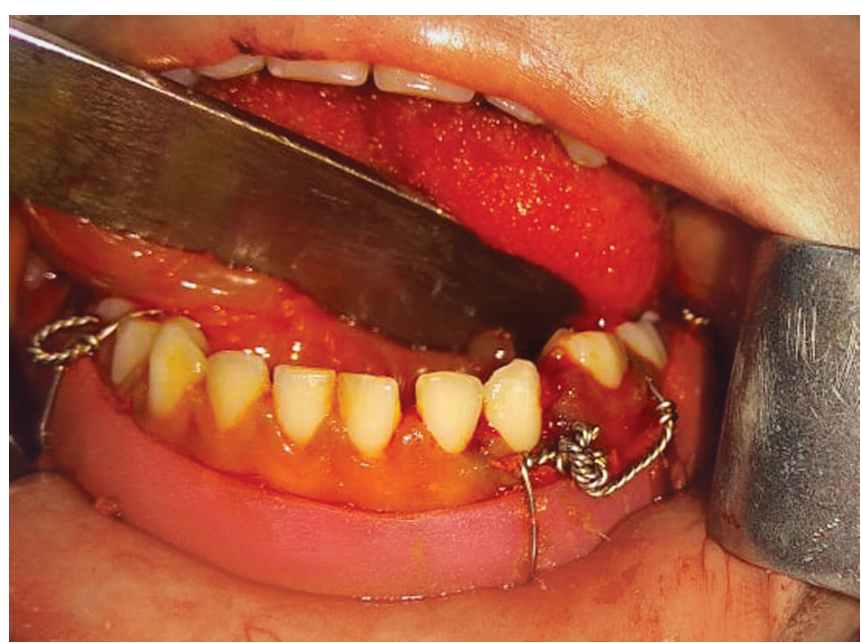

Fig 11: Open occlusal splint retained with circummandibular wiring the continuity of periosteum and the soft tissue. It fully feels the purpose of restoring the normal dental occlusion as it was before the trauma. It is a cost-effective and time-saving procedure that reduces the pain of the patient and does not pose a hindrance in the growth and development of the child.

\section{References}

1. Aizenbud D, Hagai MH, Emodi O, etal. The management of mandibular body fractures in young children. Dent Traumatol 2009;25(6),565-570. DOI: 10.1111/j.1600-9657.2009.00815.x

2. Karacor Altuntas $Z$, Ismayilzade $M$. What are the difference in pediatric mandible fractures? J Aesthet Reconstr Surg 2017;3(2):1. DOI: 10.4172/2472-1905.100034

3. Nezam S, Kumar A, Shukla JN, et al. Management of mandibular fracture in pediatric patient. Natl J Maxillofac Surg 2018;9(1): 106-109. DOI: 10.4103/njms.NJMS_54_17

4. Imahara SD, Hopper RA, Wang J et al. Patterns and outcomes of pediatric facial fractures in the united states: a survey of the national trauma data bank. J Am Coll Surg 2008;207(5):710-716. DOI: 10.1016/j. jamcollsurg.2008.06.333

5. ErikMW, William M, John W, et al. Management of pediatric mandible fractures. Otolaryngol Clin of North Am 2013;46(5):791-806. DOI: 10.1016/j.otc.2013.06.007

6. John B. John R, Elango I. Management of mandibular body fracture in pediatric patient: a case report with review of literature. Contemp Clin Dent 2010; 1(4):291-296. DOI: 10.4103/0976-237X.76406

7. Lida S, Matsuya T. Paediatric maxillofacial fractures: their aetiological characters and fracture patterns. J Craniomaxillofac Surg 2002;30(4):237-241. DOI: 10.1054/jcms.2002.0295

8. Mukherjee C, Mukherjee U. Maxillofacial trauma in children. Int J Clin Pediatr Dent 2012;5(3):231-236. DOI: 10.5005/jp-journals-10005-1174

9. Sharma S, Vashistha A, Nigam A. Pediatric mandibular fractures: a review. Int J Clin Pediatr Dent 2009;2(2):1-5.DOI: 10.5005/ jp-journals-10005-1022

10. Balakrishnan R, Ebenezer V. Management of mandibular body fractures in pediatric patients. Biomed Pharmacol J 2015;8:369-373. DOI: $10.13005 / \mathrm{bpj} / 706$

11. Gupta H, Pradhan R, Sinha VP, et al. Management of mandibular fracture in a medically compromised pediatric patient. Natl J Maxillofac Surg 2010;1(2):139-142. DOI: 10.4103/0975-5950.79216 